\title{
Determinants of Food Insecurity in Pastoral and Agro-Pastoral Households of Ethiopia
}

\author{
Lemi Gonfa \\ Lecturer, Department of Agricultural Economics, Wolaita Sodo University
}

\begin{abstract}
Food insecurity is one of the prime challenges of Sub-Sahara African countries in general and pastoral and semipastoral households of Ethiopia in particular. Many researches has been investigated on food insecurity, however the problem remains still continuing especially during unfavorable climatic season. Different research findings pointed out that pastoral areas mainly characterized by unpredictable and unstable climatic conditions, as well as ecologically fragile environment. Pastoral areas are also characterized by frequent draught, conflict, flood and food insecurity as well as inadequate facilities and infrastructure. Low human development features, manifested by very low primary \& secondary schools gross enrollment rate. The paper went ahead to discuss on the vulnerability of pastoral communities to food insecurity, the causes of food insecurity was reviewed from different literatures. Determinants of food insecurity in pastoral and agro-pastoral households of Ethiopia and finally indicted some policy implications.
\end{abstract}

Keywords: food insecurity, pastoral

DOI: $10.7176 / \mathrm{FSQM} / 85-06$

Publication date:March $31^{\text {st }} 2019$

\section{Introduction}

Sub-Saharan Africa accounts for $13 \%$ of the population and $25 \%$ of the undernourished people in the developing world. It is the developing region with the highest proportion one-third of people suffering from chronic hunger. In 14 countries in the region, $35 \%$ or more of the population were chronically undernourished in the year2001/03(FAO, 2006).

About 17 million people in the East Africa region are highly or extremely food insecure and are in need of emergency humanitarian assistance. This is mainly due to the cumulative effects of poor rainfall/droughts in pastoral and marginal cropping areas in the eastern sector of the region, civil insecurity/conflict and consequent population displacement and disruption to markets, and high food prices (FEWS NET, 2010). Drought conditions have caused livestock mortality and household asset loss and undermined pastoral household incomes and coping strategies. Livestock loss among pastoral groups, which has been close to $50 \%$ of the more drought-susceptible cattle and sheep, in some areas, means that recovery will be a long drawn experience. Because of the protracted and successive droughts, a minimum of two to three successive good seasons are required for recovery among the pastoral livelihoods. In addition, some income generation options (such as labor-intensive work schemes) will be necessary to ensure that pastoral households do not draw down on their assets (ibid).

In Ethiopia Food insecurity affects particularly people in moisture deficit highland and in the lowland pastoral areas. Even in years of adequate rainfall and good harvest, the people, particularly in low land agropastoral areas, remain in need of food assistance. This clearly reflects the deeply entrenched poverty and food insecurity situation in the country irrespective of adequate rainfall (Workneh, 2004).

Regions that are subject to intermittent or inadequate rainfall are commonly described as Ethiopia's drought-prone areas. These are also regions where years of imprudent land use have caused considerable land degradation. Although food insecurity is experienced in practically all parts of the country, it is, however, in these regions where it is most intensely felt (MoFED, 2002).

Pastoralism is a method of agricultural exploitation based upon extensive herding where movements of herds and men are the major components of the system. The human population of pastoral areas is estimated to be between $12-15 \%$ of the country of which $93 \%$ are pastoral/agro pastoral and the remaining $7 \%$ depend on other agricultural activities (hunting, petty trade, mining etc). Pastoral areas in Ethiopia are located in the Northeastern, Eastern, Southern-Eastern, and Southern, \& Southwestern part of the country (MoFED, 2002).

Livestock in the pastoral areas are the major source of food (milk and meat) and income, as well as a source of employment. They also serve similar purposes and functions for people living in urban and rural towns adjacent to the pastoral areas. Livestock contribute a significant amount to the national economy. In terms of gross national product, the contribution of livestock to the agriculture sector and the national economy is $40 \%$ and more than $20 \%$ respectively (Beruk, 2003).

However, the pastoral production system and in particular the food security and livelihood situation is highly threatened because of different man-made and natural risks. Some of the major risks and challenges the pastoral communities in the country are facing include: i) expansion of sedentary agriculture; ii) expansion of 
agricultural projects; iii) expansion of national parks inside the rangeland; iv) emergence and expansion of agropastoralism; v) encroachment of unwanted plant species; vi) conflict over rangeland resources; and vii) recurrent drought (Ibid).

Some 10 million semi-nomadic people depend primarily on grazing herds of cattle, camels, and goats, and are concentrated mostly in the dry lowland areas of Afar and Somali. Human development indicators and poverty among this group are uniformly worse than elsewhere in the country, and they have proven difficult to reach with traditional services (MoFED, 2006).

For instance in Afar According to (Bekele, 2009) the losses of livestock due to drought coupled with the deteriorating terms of trade against pastoralists worsened food insecurity in many parts of the region. The degree of food insecurity reached its climax in 2002/03 because of the intensified drought. Due to this the deterioration of food security in Afar and other pastoral areas necessitated an intensified intervention of external agents (government and NGOs) into pastoral and agro-pastoral livelihoods.

\section{Definition of Food Insecurity}

The opposite of food security is food insecurity - lack of access to an adequate diet - which can be either temporary (transitory food insecurity) or continuous (chronic food insecurity). These concepts underline the temporal dimension of food security a feature that it shares with 'sustainable livelihoods', which are essential for ensuring household food security and reducing vulnerability to food insecurity (Devereux et al., 2004).

According to FAO (2000), Food insecurity is a situation that exists when people lack secure access to sufficient amounts of safe and nutritious food for normal growth and development and an active and healthy life. It may be caused by the unavailability of food, insufficient purchasing power, inappropriate distribution, or inadequate use of food at the household level. Food insecurity, poor conditions of health and sanitation, and inappropriate care and feeding practices are the major causes of poor nutritional status. Food insecurity may be chronic, seasonal or transitory. At times when an individual, household, or community is unable to avail and access food for the above mentioned reasons then the situation could be described as a state of food insecurity.

Food insecurity is also an underlying cause of malnutrition and in extreme cases results in mortality. A high degree of food insecurity when compounded with other undesirable factors can threaten livelihoods. High risks of food insecurity and livelihoods can be expressed in terms of malnutrition, morbidity, and in extreme cases mortality (Beruk, 2003).

\section{Dimensions of Food Insecurity}

'Chronic' and 'transitory' refer to temporal dimensions of food insecurity, where the former is long-term or persistent, while the latter is short-term and temporary. Some common definitions of chronic food insecurity include: 'the inability of a household or an individual to meet the minimum daily food requirements for a long period of time' (IFAD, 1997), Persistent inability on the part of the household to provision itself adequately with food' (FAO, 2005) And 'when households are unable in normal times to meet food needs because they lack sufficient income, land or productive assets, or experience high dependency ratios, chronic sickness or social barriers'( WFP,2004).

Transitory food insecurity, on the other hand, is usually defined as: 'a sudden (and often precipitous) drop in the ability to purchase or grow enough food to meet physiological requirements for good health and activity' (Barrett et al., 2001), the sudden reduction of a household's access to food to [levels] below the nutritionally adequate level'; and (IFAD, 1997) 'When there is a temporary inability to meet food needs, usually associated with a specific shock or stress such as drought, floods or civil unrests'(DFID, 2002). Evidenced by these definitions, chronic food insecurity tends to be associated with structural deficiencies or vulnerability, while transitory food insecurity is generally a result of temporary shocks and fluctuations, but there are obvious linkages between the two.

Another temporal aspect of food insecurity is seasonal or cyclical food insecurity, defined as a 'cyclical pattern of inadequate access to food (e.g. food shortages in pre-harvest period)' (FIVIMS, 2002). Since cyclical food insecurity generally follows a sequence of known events, it can be more easily predicted than transitory food insecurity. Hence, it can be categorized as a form of 'recurrent transitory' food insecurity (Maxwell et al., 2008).

\section{Pastoral and Agro-pastoral Livelihoods}

Livelihoods are a means of making a living. They comprise ways in which people access and mobilize resources which enable them to pursue goals necessary for their survival and long-term well-being. Livelihoods are affected by natural, policy, social, economic, physical, and human factors (Beruk, 2003).

Livelihoods have become the framework through which food security is usually analyzed. While often focusing on food security as an outcome, a livelihoods approach therefore emphasizes understanding people's means of achieving this outcome: their assets, the strategies on which they rely, the constraints they face and the 
coping strategies they are forced to depend on to achieve outcomes in terms of food security and accessing other basic requirements. The emphasis is on both the means (livelihoods) and the ends (food security, health, shelter, safety) (Maxwell et al., 2008).

As a way of life and economic activity, pastoralism in Africa is one of the oldest, most resilient and most adaptive livelihoods strategies which are well suited to arid and semi-arid environments. Although there is no standard definition of pastoralism, it is often defined as a livelihood in which at least 50 per cent of a household's food income is derived from livestock. Furthermore pastoralism is characterized by mobility and in particular, the seasonal movement of livestock to access grazing resources and water. They have developed a diverse range of strategies, institutions and networks to exploit the unpredictability of arid environments to their economic advantage. Livestock mobility and the carefully controlled breeding of animals to feed selectively on the best quality pastures highly dispersed in time and space are two of the more critical strategies that allow them to create economic value rather than mere survival in difficult environments (CAADP, 2009).

A second major livelihood system is agro-pastoralism. Again there is no standard definition of agropastoralism but it involves less reliance on livestock and more reliance on crop production. Agro-pastoralism occurs in areas with relatively higher rainfall, but also involves some form of seasonal movement of livestock to grazing areas. The distinction between pastoralism and agro-pastoralism is often blurred because depending on rainfall other trends; households may adopt either of these two livelihood strategies in different years (Ibid).

Pastoral areas are generally marginal to intensive crop production. Consequently, livestock production appears to be the best and, in some areas the only, option under the existing technologies (Ahmed et al., 2002). However, as a result of challenges (mainly drought) which have caused rapid deterioration of pastoral livelihoods, pastoralists usually seek out alternative means of survival, at least on transitory basis. Since opportunities are lacking in most pastoral areas, resorting to agriculture is the main option that pastoralists pursue. Indeed, a growing trend toward crop cultivation is now observable in many pastoral areas of Ethiopia (Beruk, 2003).

\section{Vulnerability of Pastoral Communities to Food Insecurity}

Pastoral communities are highly vulnerable to food insecurity. Vulnerability to food insecurity is aggravated by underlying causes, external shocks, and internal capacities to cope. Underlying vulnerability is very much associated with structural conditions, rendering some populations more vulnerable to acute food shortages, such as poverty, lack of basic services, etc. External shocks are associated with the actual emergency or stress factors, such as recurrent drought, floods, earthquake, conflict, displacement, etc. Internal capacities to cope refer to peoples' capacities to cope with the shock, and depend on factors such as social networks, assets, and political status. Based on the above scenario, pastoral communities are currently vulnerable to food insecurity even with the slightest external shock (Beruk, 2003).

It also commonly observed that lowland communities and pastoralists in Ethiopia are vulnerable to food insecurity due to multiple ecological, economic and infrastructural problems. These problems include recurrent drought, conflict over rangelands and encroachment of unwanted plant species (Ibid).

Food insecurity in pastoralist areas can also be viewed in terms of chronic food insecurity, and transitory or acute food insecurity. Those vulnerable to chronic hunger are households that are either subjected to frequent or severe and regular food insecurity, or households that have low resilience, or both. In contrast, households that suffer acute or transitory food insecurity or hunger do so over a shorter but intense period, such as the lifethreatening periods of drought (CAADP, 2009). At present, the main instrument for dealing with both categories of food insecurity in pastoralist area is food aid.

\section{Understanding the Causes of Food Insecurity}

In any given context, food security concerns may be due to either inadequate physical availability of food supplies, poor access among a specific segment of the population, or inadequate utilization (Riely et al., 1999).

According to USAID (1995) many factors interact to create food-insecure situations: chronic poverty, low agricultural productivity, high rates of population growth, civil conflict, poor infrastructure, ecological constraints, inappropriate economic policies, limited arable land and even cultural practices developed over many years. These are not discrete, independent factors, but related elements of the food security equation. The chief cause of food insecurity is chronic poverty: persistent lack of economic opportunity either to produce adequate food or to exchange labor for the income to purchase adequate food.

The factors which are precipitating food insecurity and livelihood vulnerability are not well understood in the some pastoral areas of Ethiopia. Thus unless the root causes of the crisis are identified and addressed properly, responding to the current emergency only will not improve the severe food security and livelihood problems of pastoralists. The root causes of hunger and poverty in the pastoral areas-insecure and inadequate land tenure and lack of investment in rural infrastructure, water shortage, rangeland degradation, dependency on livestock, poor public service, and conflict, poor basic services such as education, health and communication 
amongst others \& have not adequately been addressed (Phipott et al., 2005; PFE,2007).

Natural resources shrinkage, recurrent drought and population pressure coupled with pastoral policy constraints, mainly lack/inadequacy of the social and economic services, have exceeded the pastoralists' traditional mechanisms of coping with the fragile and harsh climatic conditions they used to live in. The resultant effects of these deep-rooted challenges have brought about depletion of assets (especially the livestock), food insecurity, and conflict, which in turn result in overall pastoral livelihood insecurity and crises. In totality, the artificial and natural calamities are threatening the existence of the pastoral livelihood systems in which the growing of poverty both in depth and dimensions in pastoral regions can be taken as an indicator of the challenges the pastoralists are facing today (PFE, 2004).

\section{Food Security Situation in Pastoral and Agro-Pastoral Areas of Ethiopia}

Pastoralism in Ethiopia constitutes a unique and important way of life for close to 15 million people living in about 7 regions in the country. The pastoral areas mainly characterized by unpredictable and unstable climatic conditions, as well as ecologically fragile environment. Pastoral areas are also characterized by frequent draught, conflict, flood and food insecurity as well as inadequate facilities and infrastructure. Low human development features, manifested by very low primary \& secondary schools gross enrollment rate [20 \& 3\% only]; characterize extreme poverty in the pastoral regions (PFE, 2007).

Food security situation in Ethiopia is highly linked up to severe, recurring food shortage and famine, which are associated to recurrent drought. Currently there is a growing consensus that food insecurity and poverty problems are closely related in the Ethiopian context. The minimum average calories requirement is estimated at $2,200 \mathrm{kcal}$ per person per day (MoFED, 2002). More than $50 \%$ of the population does not have access to this minimum, the current average figure for the country being not more than 1,700 kcal. The food insecure social groups in Ethiopia include: the urban unemployed, people in areas of conflict, destitute peasants, pastoralists who depend on markets for cereal supply and the refugees from neighboring countries, mainly from Somalia and Sudan. A number of studies have confirmed that there is severe food insecurity in Ethiopia covering a wide range of areas and affecting a large number of people (FDRE 2002).

The poverty situation in the pastoral areas doesn't show significant changes compared with other regions in the country; Per capita calorie intake levels are also very low in the pastoral regions compared with the National average. For instance, per capita calorie in rural Afar has only slightly increased from $1617 \mathrm{kcal}$ in 2000 to 1861 in 2005 in five years period. It has shown a decline in Somali [from $2402 \mathrm{kcal}$ in 2000 to $2196 \mathrm{kcal}$ in '05] (PFE, 2007).

\section{Empirical Reviews on Determinants of Food Insecurity}

Different studies have been made on household food insecurity in general and determinants of food insecurity in particular in different areas. Some of the studies that were made are summarized below.

The contemporary debates on vulnerability of households to food insecurity have given fertile ground to disaggregate the concept of poverty in the context of food and nutritional security (SLE, 1999; as cited in Ayalneh, 2002). The problems of poverty and food insecurity are closely related, though they are by no means synonymous. In the study, their association has been explained from their definitional and causal points of view. The number of people suffering from food insecurity is determined on the basis of resource required to secure sufficient food for adequate diets while poverty is defined in terms of the income level below which people are incapable of accessing sufficient food for a healthy and working life. In light of this, the determinants employed in the poverty model are also used in food insecurity model. That is, in the study, the characteristics of the households such as age of, sex of, education of household heads, dependency ratio, family size, and ownership of oxen, land holding size, income and geographical locations were also used to explain the probability model to characterize a household poor or non-poor.

The above evidence was also cited in Sisay (1995) by stating food insecurity is directly related to poverty since chronic food insecurity is caused by the inability of the household to produce, or to have access to food. The same source revealed that as recent empirical evidences suggested the reduction of poverty and food insecurity has been achieved by pursuing a dual strategy of: first, promoting the productive use of unskilled labour primarily located in rural areas and upgrading the quality of that labour through investments on health, education, nutrition, and mobility; and second, providing basic social services in the areas of primary education, health, nutrition and family planning along with targeted transfers to the poorest and most food insecure groups.

A study done by Mohammed (1995) demonstrated that livestock play a major role in food security at national and household levels. Livestock are the living bank for pastoralists and agro-pastoralists. They are means of accumulating wealth and are sources of foreign earrings. In his study he also mentioned several factors such as animal diseases, poor genetic improvement, feed supply, and policy factors that negatively contribute to livestock production and affect its role in ensuring food security. The same source revealed that annual loss due to animal diseases is as high as $30-50 \%$ of the total value of livestock production. 
A study conducted by Ayalneh (2002) in Hitosa, Haramaya, and Merhabete Districts demonstrated that factors that have contributed to transitory and chronic food insecurity in rural Ethiopia are manifold and varied, ranging from political and socio-economic to environmental. Among the political factors he listed inappropriate agricultural and marketing polices, and political conflict both at national and local level while demographic characteristics of rural households, inadequate resource endowments, inadequately developed infrastructure such as school, health institution and roads, etc., are among socio-economic factors.

Gulled (2006) studied food insecurity and coping strategies of agro-pastoral households in Awbare woreda of Somali Regional State using logistic regression model. His results showed that age of the household head, sex of the household head and household size in $\mathrm{AE}$ were found to have positively affect food insecurity status of the households. While total cropping land in Ha, oxen ownership and remittances income in Birr affect food insecurity status of the household negatively.

Yusuf (2007) made an assessment of Determinants of Food Security in Pastoral and Sedentary Livelihoods: The Case of Erer District Shinille Zone, Somali Regional State. Using binary logit model according to his result annual income and livestock holding affect household food insecurity negatively whereas family size, age of the household head, spread of livestock diseases are identified to influence household food insecurity positively. The possible explanation is as family size increases, the amount of food for consumption in one's household increases thereby that additional household member shares the limited food resources in the household. In addition the more the household head is older, the less labor force the household has to carry out both livestock and crop production and reason for the positive correlation between spread of livestock disease and food insecurity is that in areas where livestock production is predominantly very essential, the spread of livestock disease can directly or indirectly affect household access to food. It makes a livestock infectious, sick or lead to mortality while livestock is one of the major sources of cash income for the households in the study area. Hence in a situation where spread of livestock disease is severe, the probability of a household to loss his livestock is very high and so can easily be vulnerable to food insecurity.

Hilina (2005) made an assessment of Dimensions and Determinants of Poverty in Pastoral Areas of Shinile Zone in Somali National Regional State using logistic regression model. According to his result age of household head, total family size \& dependency ratio and animal disease incidences expressed in terms of lost TLU/AE were found to have positive association with poverty of the household. Meanwhile, income from livestock and livestock products per AE, livestock owned expressed in terms of TLU/AE, non-farm income per $\mathrm{AE}$, age at first marriage, selling of milk and pasture management practices were found out to have strong negative association with the household's poverty status.

Kefelegn (2007) made an assessment on Dimensions and Determinants of Agro-Pastoral Households Poverty in Kebribeyah District of Somali Regional State using logistic regression model he found that non-farm income, livestock owned per adult equivalent, income from sale of milk and milk products and productivity of land have negative impact on the poverty status of the household while total household size in adult equivalent and livestock died have positive association with poverty of the household. The possible explanation can be those households with many children could face poverty because of high dependency burden. This shows that those farmers with large economically non-active members in family tend to be poor than those with small family size and an increase in livestock died may lead to lower number of animals per adult equivalent which has direct impact on the reducing on annual income.

Abebaw, (2003) made an assessment of Dimension and Determinants of Food Insecurity among rural households in rural Dire Dawa Area, Eastern Ethiopia, The logistic regression model results make known that annual household income, amount of credit received, irrigation use, age of the household head, educational status of the household head, cultivated land size and total livestock owned have negatively affect food insecurity status of the households. While family size and number of oxen owned affect food insecurity status of the household positively. The likely explanation is that in an area where households depend on less productive agricultural land, increasing household size results in increased demand for food. But this demand will not be matched with the existing food supply so ultimately end up with food insecurity and there may be households in the study area cultivate their farmland using hand tools. Moreover, some farm households even if they are using oxen for farm operation it could not be possible to see the effect because their farm size is small. However, oxen could serve as a store of wealth and disposed during time of severe food shortage. But this is not practiced in the area, because farmers think that regaining such asset is by far difficult.

Dereje (2008) carried out a study on Determinant of Poverty in case of Rural Dire Dawa Administration, Eastern Ethiopia. The binary logit model results make known that among the explanatory variables included in the model, income from non-farm activities, tropical livestock unit, size of irrigable land, credit experience of a household head and number of ox owned influence poverty status of the households negatively whereas family size and dependency ratio influence household poverty status positively. The possible explanation is that a family with large family size could not be able to provide sufficient basic needs to family members because most of them are children and not economically active. 
Kifle and Yosef (1999) pointed out that many the natural and human-induced causes that made Ethiopia a Food-insecure country at the national level are fragile natural resource base, insufficient and variable rain fall, improper farming practices, and inaccessibility to productive resources (such as rural credit). In addition, diminishing landholdings and tenure insecurity, poor development of human resources, poor storage technology, inaccessibility to transport infrastructure, heavy work load on women, poor health condition, lower productivity of livestock, high level of unemployment, inappropriate use and non-integrated free distribution of food aid, socio-cultural barriers, and lack of baseline information were identified as the determinants of food insecurity.

Using the binary logit model in Dirre District, Borena Zone of Oromia National Regional State, Siraj (2007) made an assessment on Livelihood Diversification among Pastoralists he found that livestock asset, education level of the household head, access to road and household size were the important determinants of poverty status of the household head in the study District.

\section{SUMMARY AND CONCLUSION}

Food insecurity is the most critical problem facing a large number of both settled and pastoral households in Ethiopia. That is, the problems of drought, diseases, livestock feed, institutional and policy factors, land/rangeland degradation, low agricultural productivity and other-related problems, which result in food insecurity and poverty, are particularly severe in the lowland areas of the country in which pastoral production system is dominant.

In the lowlands of Ethiopia, pastoralism is the mode of production best suited to an arid and unstable environment. As a result, instead of crop production, livestock development has the potential to improve the welfare of many poor rural families and to contribute significantly to the national economy. But the solution for the problem of poverty in pastoral areas should not be just livestock development. Pastoralist households also suffer from poor access to social and economic services. In the past, pastoral area development had received almost no attention from policy-makers, and pastoralists continue to be marginalized economically, socially and politically. This has forced the pastoralists to live in abject poverty, resulting in food insecurity and conflicts.

The pastoralists pursue their livelihoods in subsistence based, mixed livestock management of camels, cattle, goats and sheep. Livestock management is often based on mobility and labor allocation for herding of different species and age categories. Because of the decline in livestock population per household, caused by drought, some pastoralists started crop farming. In order to cope with the decline in their livelihood, the interest for changing the livelihood system by diversifying means of earning is increasing. One possibility is crop production. But this vision of engaging in farming cannot be realized under the current harsh climatic condition. It requires investment in irrigation system and building the farming skills of the pastoralists.

The traditional mobile way of life has been threatened by recurrent drought. Partial settlement of the families, keeping on mobility of the livestock while settling the family members, is the future vision of the pastoral communities. The settlement requires, however, social services such as school, public health and income generation activities particularly for women so that they can earn and subsist their families.

Due to the recurrent drought and declining rangeland productivity, the extent of food insecurity is deepening in pastoral and agro-pastoral areas. Income diversification by involving in income generation activities is growing. Petty trade, organizing women to provide services such as grain mill, grain and industrial products marketing, marketing of livestock products, processing of milk, etc. have been identified by the communities as potential areas of income generation.

There are no formal credit and micro-finance services in Pastoral and Agro-pastoral areas to support the income generation activities. Hence market and public services infrastructure development has been found crucial for sustainable development by increasing access income generation, education, better human and veterinary services, and ultimate social and economic development.

Unless assets diversification mechanisms are in place, decline in livestock assets as a result of disease and drought may lead to food insecurity and poverty in pastoral and Agro-pastoral areas. Due to this creating a strong and systematic advocacy and lobby system and a capacity better to understand the dynamics of livelihood systems in relation to the broader policy environment is an essential pre-requisite for sustainable pastoral and Agro-pastoral development.

\section{REFERENCES}

Abebaw Shimeles, 2003. Dimensions and determinants of food insecurity among rural households in Dire Dawa area, eastern Ethiopia. An M.sc Thesis Presented to the School of Graduate Studies of Haramaya University. 112p.

Ahmed, A.G.M, A. Azeze, M. Babiker and D. Tsegaye (2002) Post-Drought Recovery Strategies among Pastoral Households of the Horn of Africa: A Review. OSSREA, Development Research Report Series no. 3.

Ayalneh Bogale. 2002. Land degradation, Impoverishment and Livelihood Strategies of Rural Households in Ethiopia: Farmers' Perceptions and Policy Implications. Aachen: Shaker. Institutional Change in 
Agriculture and Natural Resources; Bd. 8, Berlin. March 2002.

Beruk, Y., 2003. Food Security Situation in the Pastoral Areas of Ethiopia. PP.1-3. National Pastoral Programme Coordinator, Oxfam GB).

CAADP (Common Market for Eastern and Southern Africa Comprenhensive African Agriculture Development Programme), 2009. Policy Framework for Food Security in Pastoralist Areas consultative Draft December 2009. PP. 2-4. (CAADP) Pillar III.

Dereje Zewdu, 2008. Determinants of Poverty in Rural Dire Dawa Administration, Eastern Ethiopia. An M.sc Thesis Presented to the School of Graduate Studies of Haramaya University. 98p.

Devereux S., B.Bob, H.Karim, S.Jeremy, S.Helen \& W.David, September 2004. Improving the Analysis of Food Insecurity. Food Insecurity Measurement, Livelihood Approaches and Policy Application in FIVIMS. PP. 3.

DFID (Department for International Development),2002.Food Security Strategy and Priorities for Action Eliminating Hunger London.

FAO (Food and Agricultural Organization), 2000. The State of Food Insecurity in the World Rome, Pp. 26. 2005. Assessment of the World Food Security Situation, Committee on World Food Security, Thirty-first session, 23-26 May 2005.

-----------, 2006. The State of Food Insecurity in the World 2006 (Rome: FAO), Pp. 23.

FDRE (Federal Democratic Republic of Ethiopia), 2002. Sustainable Development and Poverty Reduction Program. Addis Ababa.

FEWS NET (Famine Early Warning Systems Network), 2010. EAST AFRICA Regional Food Security Outlook October 2009 to March 2010. PP. 1-2. FEWS NET East Africa Nairobi, Kenya. FEWS NET is a USAIDfunded activity. www.fews.net/east.

FIVIMS (Food Insecurity and Vulnerability Information and Mapping Systems), 2002. Understanding Food Insecurity and Vulnerability: Tools and Tips (Rome: FAO).

Gulled Abdullahi, 2006. Food Insecurity and Coping Strategies of Agro-Pastoral Households in Awbare Woreda, Somali Region Ethiopia. An M.sc Thesis Presented to the School of Graduate Studies of Haramaya University. 63p.

Hilina Mikrie, 2005. Dimensions and Determinants of Poverty in Pastoral Areas of Eastern Ethiopia: The Case of Shinile Zone In Somali National Regional State. An M.sc Thesis Presented to the School of Graduate Studies of Haramaya University. 90p.

IFAD (International Fund for Agricultural Development), 1997. Food Security, Poverty and Women: Lessons from Rural Asia.

Kefelegn Abera, 2007. Dimension and Determinants of Agro-Pastoral Household Poverty in Kebribeyah District, Somali Regional State. An M.sc Thesis Presented to the School of Graduate Studies of Haramaya University. 64p.

Kifle Lema and Yosef Gebre-hiot. 1999. The food security situation in Ethiopia; Concepts, Status and Trends. In the Proceeding of the First National Workshop of NOVIB Partners Forum on Sustainable Land Use. Addis Ababa, Ethiopia.

Maxwell D., S.Kate, S.Amanda, M.Mercy, E.Rebecca and W.Mackinnon, 2008. Emergency food security interventions, Good Practice Review Number 10.pp.7, 10, 14 \& 26 Humanitarian Practice Network (HPN) Overseas Development Institute 111 Westminster Bridge Road London, SE1 7JD United Kingdom.

MoFED (Ministry of Finance and Economic Development), 2002. Ethiopia: Sustainable Development and Poverty Reduction Program. PP. 34, 71 \& 76. Federal Democratic Republic of Ethiopia (FDRE) Ministry of Finance and Economic Development (MOFED) July, 2002 Addis Ababa Ethiopia.

, 2006. Ethiopia: Building on Progress A Plan for Accelerated and Sustained Development to End Poverty (PASDEP) (2005/06-2009/10) Volume I: Main Text Ministry of Finance and Economic Development (MoFED). PP. 50. September, 2006 Addis Ababa.

Mohammed Mussa. 1995. Livestock and Food Security in Ethiopia: An Overview. In: Mulat D., Wolday A., Simeon E., and Tesfaye Z., eds., Food Security, Nutrition and Poverty alleviation in Ethiopia, Addis Ababa, Agricultural Economics Society of Ethiopia.

PFE (Pastoralist Forum of Ethiopia), 2007. Proceedings of the Fourth National Conference on Pastoral Development in Ethiopia, Millennium Development Goals and Pastoral Development: Opportunities \& Challenges in the new Ethiopian Millennium UN ECA Conference Hall August 29-30, 2007 Addis Ababa.p26.

Phipott. J, Asnake.Abera and Kassaye.Hadgu, 2005. Livelihoods/Emergency Assessment in Afar Region for Oxfam International, February 2005.vp.

Riely.F., M.Nancy, C.Bruce, B.Laura, and K.Eric, 1999. Food Security Indicators and Framework for Use in the Monitoring and Evaluation of Food Aid Programs.pp. 12-14. Published January 1999 Food and Nutrition Technical Assistance Project (FANTA), Academy for Educational Development, 1825 Connecticut 
Avenue, NW, Washington, D.C. 20009-5721.

Siraj Abdulahi, 2007. Livelihood Diversification among the Pastoralists: The Case of Dirre District, Borena Zone of Oromia National Regional State. An M.sc Thesis Presented to the School of Graduate Studies of Haramaya University. 96p.

Sisay Asefa. 1995. Perspectives on Agricultural Policy, Rural Poverty, and Food Security in Ethiopia. In: Mulat D., Wolday A., Simeon E., and Tesfaye Z., eds., Food Security, Nutrition and Poverty alleviation in Ethiopia, Addis Ababa, Agricultural Economics Society of Ethiopia.

SLE (Seminar für Ländliche Entwicklung). 1999. Food Security and Conflict: A Participatory Development Concept for Integrated Food Security Programme Trincomalee, Sri lanka. Margraf, Weikersheim: Center for Advanced Training in Rural Development.

USAID (United States of American International Development), 1995. "Food Aid and Food Security: USAID Policy Paper," February 1995, P. 7-10

WFP (World Food Program), 2004. Emergency Needs Assessment, WFP/BE.1/2004/4-A Rome.

Workneh Negatu, 2004. Reasons for Food Insecurity of Farm Households in South Wollo, Ethiopia: Explanations at Grassroots. pp. 2. Institute of Development Research (IDR), Addis Ababa University CRSP (Collaborative research support programme).

Yusuf Aliyi Hussen, 2007. Determinants of Food Security in Pastoral and Sedentary Livelihoods: The Case of Erer District, Shinille Zone, Somali Regional State. An Msc Thesis Presented to the school of Graduate Studies of Haramaya University. 67P. 